\title{
O SUblime NA CRÍtica DA RAZÃO PRÁTICA
}

Emanuele Tredanaro (UFLA) ${ }^{2,3}$

emanuele.tredanaro@ufla.br

Resumo: $\mathrm{O}$ trabalho visa uma leitura da teoria da sublimidade na Crítica da razão prática, a partir da análise das passagens nas quais, em particular na conclusão da obra e no terceiro capítulo da Analítica da razão prática pura, Kant oferece respaldo textual para destacarmos certa distância teórica com relação à concepção estética do sublime sucessivamente apresentada na Critica da faculdade do juízo, notadamente na formulação geral do \$23. Para isso, e tendo como plano de fundo uma perspectiva contrastiva de interpretações que aproximam segunda e terceira Críticas quanto ao sublime, sugerimos que, nessas duas obras, há variações referentes tanto à dinâmica envolvida pelo sublime quanto ao seu objeto de referência, assim como no que tange à caracterização dos sentimentos de admiração e respeito mediante os quais, segundo Kant, o sublime se expressa.

Palavras-chave: Kant; Sublime; Respeito; Admiração.

Talvez uma das passagens mais célebres da inteira filosofia kantiana seja o incipit da conclusão da Crítica da razão práti$c a(K p V)$ :

Duas coisas enchem o ânimo de admiração e de reverência sempre renovadas e crescentes quanto mais frequente e continuamente a reflexão se ocupa delas: o céu estrelado sobre mim e a lei moral em mim. Eu não preciso buscá-las e simplesmente supô-las como mergulhadas em

\footnotetext{
${ }^{1}$ Recebido: 25-07-2020/ Aceito: 02-02-2021/ Publicado online: 15-04-2021.

${ }^{2}$ Professor adjunto na Universidade Federal de Lavras (UFLA), Belo Horizonte, MG, Brasil.

${ }^{3}$ ORCID: https://orcid.org/0000-0001-8475-2637.
} 
obscuridades ou no transcendente, fora de meu horizonte; eu as vejo diante de mim e as conecto imediatamente à consciência de minha existência (KpV, AA 05: 161.29-162.03).

Para Kant, a realidade da lei moral, por ser imediatamente ligada à consciência de minha existência (Bewußtsein meiner Existenz), é inquestionável tão quanto a do céu estrelado. Igualmente inquestionável é a realidade do sentimento de admiração (Bewunderung) e reverência (Ehrfurcht) que ambos, céu estrelado e lei moral, suscitam em nós, à medida que tornam-se objeto de reflexão. Apesar de se referir ao mundo sensível ou ao suprassensível, Kant declara que a atividade contemplativa da qual qualquer ser humano é capaz, é acompanhada - ao menos em seu surgimento - por sentimentos que a alimentam e intensificam. Assim, dentro da tensão dual que caracteriza sua filosofia em geral e sua visão antropológica em particular ${ }^{4}$, Kant especifica as afirmações iniciais, mostrando como, ao reenviar diretamente à nossa existência da qual somos imediatamente conscientes, a contemplação da finitude e infinitude, da conexão causal mecânica e conexão necessária por liberdade, da vida animal e vida espiritual, não é resultado de uma mera hipótese, nem sonho de visionário além do horizonte humano, mas sim ligação real do ser humano tanto com o mundo sensível (Sinnenwelt), em uma relação meramente contingente, quanto com seu próprio eu (Selbst) e personalidade (Persönlichkeit) $^{5}$, em uma relação universal e necessária (cf.

\footnotetext{
4 Para uma articulada apresentação da concepção antropológica de Kant, cf. LOUDEN 2011. Sobre as abordagens transcendental e empírica da antropologia kantiana, cf. COHEN 2008, p. $506-$ 514 e FRIERSON 2013, p. 11-71.

5 Sobre as noções de pessoa e personalidade na KpV, cf. MOHR 1988, p. 289-319 e ERTL 2010, p. 217-230. Para uma análise em chave antropológica, cf. GERHARDT 2009, p. 269-291.
} 


\section{$\mathrm{KpV}$, AA 05: 162.03-11).}

É de se notar, portanto, que, pela perspectiva do ser humano em geral - da razão comum como Kant se expressa, e como veremos em breve - a qual está em foco nesse primeiro movimento da conclusão da $K p V$, não apenas na esfera moral, mas também na referente à reflexão sobre a natureza, está envolvida uma dimensão sentimental, originária e imediata, precedente ao conhecimento e discurso científico. Trata-se do momento em que o ser humano reconhece sua conexão (Verknüpfung erkennen) com o mundo a ele exterior ou interior, ainda de maneira irrefletida, ou seja, sem que esteja ainda pressuposta aquela investigação racional sistemática, à qual, por sua vez, nos incentiva o próprio viés sentimental de imediata admiração e reverência em frente da natureza ou da nossa interioridade.

A partir dessas premissas, na estruturação da conclusão da $K p V$ sobressai-se um fio condutor que leva a um segundo movimento argumentativo, no qual Kant assinala a necessidade da passagem desse primeiro estágio de imediatez sentimental percebida pela razão comum sob forma de deslumbre reverente, para o sucessivo de investigação científica respaldada na análise da razão, "buscada criticamente e introduzida metodicamente" (KpV, AA 05: 163.24) ${ }^{6}$, conforme Kant evidencia na última página da $K p V$. Assim Kant introduz esse segundo movimento: "a admiração e o respeito podem certamente incitar a investigação, mas não podem substituir a sua ausência. $\mathrm{O}$ que se há então de fazer para

6 Pelo andamento do raciocínio kantiano, ecoa aqui, ao menos em certa medida, a sugestão de análise já proposta explicitamente na Fundamentação da metafísica dos costumes (GMS), a partir da trajetória assinalada desde o prefácio da obra de 1785, assim como pelo título da primeira seção. 
implementar essa investigação de maneira útil e adequada à sublimidade do objeto?" (KpV, AA 05: 162.21-23).

Sem que seja nossa pretensão seguir o fio condutor assinalado, no entanto, aqui, nos interessa resgatar este último excerto, por ele oferecer elementos terminológicoconceituais úteis ao nosso exame do sublime na $K p V$. Notadamente, gostaríamos de frisar que, ao dar continuidade ao raciocínio inicial com um segundo movimento argumentativo, Kant faz uso explícito das noções de 'sublimidade' (Erhabenheit) e 'respeito' (Achtung), trazendo à tona os que acreditamos serem os polos conceituais da questão debatida: por um lado, em geral, Kant reconhece sublimidade ao objeto da investigação, seja esta dedicada à natureza, ou à moral; por outro lado, tal sublimidade é apresentada, no início da conclusão da $K p V$, como imediatamente sentida por nós sob forma de admiração e reverência, sendo agora caracterizada como sentimento de admiração e respeito, isto é, através daquele sentimento ligado de modo todo peculiar à lei moral, o qual, como é notório, empenha a teorização kantiana não apenas na $K p V^{7}$.

Nesse sentido, não nos parece casual a distinção que Kant ressalta logo antes de começar o segundo movimento argumentativo, a saber, a distinção entre duas espécies de contemplação, mesmo que tenha sido previamente estabelecido ambas pertencerem, por assim dizer, ao único gênero da sublimidade.

A primeira contemplação de uma quantidade inumerável de mundos aniquila, por assim dizer, a minha importância como criatura a-

7 Cf. NOLLER 2019, p. 1-18. 
nimal que tem de devolver ao planeta (um mero ponto no universo) a matéria da qual era feita, depois de ter sido dotada de força vital por um curto período de tempo (não se sabe como). A segunda contemplação, ao contrário, eleva infinitamente o meu valor enquanto inteligência, mediante a minha personalidade, na qual a lei moral manifesta uma vida independente da animalidade e mesmo de todo o mundo sensível (KpV, AA 05: 162.12-18).

O sentimento de admiração e reverência, quando provado ao contemplarmos o mundo físico, nos nulifica (vernichtet). Mais exatamente: faz-nos sentir nossa irrelevância enquanto corpo entre corpos, conglomerado de matéria destinado a dissolver-se enquanto tal, como qualquer outro. De modo especularmente oposto, quando provado ao contemplarmos o mundo inteligível, o sentimento de admiração e reverência nos ergue $\left(e r h e b t^{8}\right)$, por reconhecermos a unicidade do nosso valor como seres inteligentes e pessoas morais.

Provavelmente por interessar-lhe completar a questão introduzida desde o início da conclusão da $K p V$ - como dito, com um segundo movimento que dê sequência ao raciocínio seguindo um fio condutor -, Kant é parco nos argumentos que apontam para o hiato entre o efeito em nós oriundo da sublimidade perante a natureza, e o efeito em nós oriundo da sublimidade moral. Todavia, não podemos deixar de salientar, que, se, por um lado, é evidente que Kant está refletindo sobre a investigação tanto física como moral nos termos da sublimidade, por outro lado, parece menos pacífico compreender tout court a sublimidade

8 Mesmo que de passagem, note-se que o verbo 'erheben' compartilha o mesmo radical com o substantivo 'Erhabenheit' (e com o adjetivo 'erhaben' e sua substantivação neutra 'das Erhabene'), reenviando à mesma família semântica que aponta para a elevação. 
da lei moral como antecipação ou transposição do sublime estético teorizado posteriormente na Crítica da faculdade do juizo $(K U)^{9}$, isto é, lendo, em retrospectiva, à luz do sentimento do sublime estético da $K U$, o sentimento do respeito pela lei moral apresentado nos escritos de filosofia moral da década de 80. Seja a última passagem citada, seja a introdução do sentimento específico do respeito ao início do segundo movimento argumentativo, nos fazem tender para outra leitura, segundo a qual, na $K p V$, reconhecer sublimidade ao objeto de contemplação não implica reconhecer-lhe sublimidade nos termos da teoria estética exposta na KU. De resto, o próprio apelo kantiano à sublimidade ao longo da $K p V^{10}$ também parece confirmar não haver indícios consistentes de que a sublimidade expressa pelo viés do senti-

\footnotetext{
9 Assim propõe, por exemplo, a interpretação clássica de Lewis W. Beck, o qual aponta para uma transposição de termos e conceitos da teoria estética para a teoria moral, quando frisa o caráter não apenas metafórico da sublimidade da lei moral na $K p V$ : "A sublimidade da lei moral é mais que uma metáfora para Kant. Não só ele usa a linguagem da estética do sublime para descrever a lei moral, mas também fornece uma interpretação análoga das origens do sentimento da sublimidade estética e do respeito. Em ambos há humilhação ou impedimento de nossa natureza sensível (nossa faculdade perceptiva e imaginação, no sublime; nosso sentimento de valor, no respeito), que ocasiona uma dor que, por sua vez, é transmutada em uma espécie de euforia pela descoberta em nós mesmos de um poder superior àquele que nos humilhou (no sublime) e também superior àquele poder em nós que foi humilhado (em ambos os sentimentos do respeito e do sublime)" (BECK 1984 [1960], p. 220). Já, mais cautelosamente, Paul Guyer e Robert R. Clewis sugerem que sentimentos e julgamentos estéticos podem fornecer apenas uma espécie de indicação de que somos livres e, portanto, auxiliar na resolução do problema da transição entre moralidade e natureza, mais exatamente, da promoção e realização da liberdade moral na ordem natural (cf. GUYER 2005, p. 222-241; CLEWIS 2015, p. 149-168).

10 São apenas quatro as passagens em que Kant trata da sublimidade na $K p V$. Uma é a já citada, presente na conclusão. As outras encontram-se todas no primeiro livro, A analítica da razão prática pura: a primeira, na última página do segundo capítulo, Do conceito de um objeto da razão prática pura, mais especificamente, na seção, Da típica da faculdade de julgar prática pura (KpV, AA 05: 71); as outras duas, ao fim do terceiro capítulo, Dos móbiles da razão prática pura, antes da Elucidação crítica da analítica da razão prática pura (KpV, AA 05: 87-88). Por sua vez, o adjetivo sublime (erhaben) é sempre usado como sinonímico de elevado, nobre (edler), inclusive frequentemente acompanha este último. Só em um caso - como veremos, enfatizado por Kant - o adjetivo 'sublime' nos assinala uma passagem teoricamente relevante.
} 
mento de respeito esteja sendo pensada, já em 1787/88, de acordo com o sentimento a priori do sublime estético de 1790; antes, parece-nos haver sinais de discordância entre as duas fases teóricas.

De modo exemplar, entre as quatro ocorrências do termo Erhabenheit na $K p V$, Kant evoca a sublimidade ao encaminhar-se para a conclusão do terceiro e último capítulo da Analítica, dedicado aos móbiles da razão prática pura, e o faz em um contexto lexical e conceitual que recorda de perto o da conclusão da $K p V$.

Essa ideia da personalidade, ideia que desperta o respeito e coloca diante de nossos olhos a sublimidade de nossa natureza (segundo a sua destinação) ao fazer notar ao mesmo tempo a falta de adequação de nossa conduta em vista dela e ao abater assim a arrogância, é natural e facilmente observável até mesmo para a razão humana mais comum (KpV, AA 05: 87.29-32).

Claros são os elementos compartilhados com a conclusão da $K p V$ : o recurso à noção de respeito; a menção da ideia de personalidade; a explicitação do ponto de vista da razão comum. Todavia, à primeira vista, parece haver discrepância teórica entre as afirmações da conclusão da $K p V$, em que - lembremos - apenas a sublimidade perante a natureza nos faz sentir nulos, ao passo que a sublimidade moral produz em nós só um efeito de elevação. Nessa passagem do terceiro capítulo da Analítica da $K p V$, parece que a dinâmica do sublime realmente antecipe de alguma maneira o duplo movimento, descendente e ascendente, atribuído por Kant ao sublime estético em sua teorização na KU. Todavia, um olhar mais atento nos mostra que, nessa passagem da $K p V$, Kant não está se referindo à sublimidade nos termos do sublime estético como introduzido na KU. Na 
obra de 1790, ao início da Analítica do sublime, no §23, Kant oferece a definição geral e mais abrangente do sentimento do sublime, contrastando-o com o sentimento do belo.

Enquanto o belo comporta diretamente um sentimento de promoção da vida, e por isso é vinculável a atrativos e a uma faculdade de imaginação lúdica, o sentimento do sublime é um prazer que surge só indiretamente, ou seja, ele é produzido pelo sentimento de uma momentânea inibição das forcas vitais e pela efusão imediatamente consecutiva e tanto mais forte das mesmas (KU, AA 05:244.28245.05).

São lícitas algumas observações a respeito da dinâmica da sublimidade exposta por Kant. Na passagem do terceiro capítulo da Analítica da $K p V$, ao pensarmo-nos como pessoas, o sentimento da sublimidade de nossa destinação ${ }^{11}$, de um lado, e, de outro, o de inadequação - à tal destinação de nossa conduta concreta, bem como o abate de nossa arrogância (Eigendünkel niederschlagen), ocorrem ao mesmo tempo (zugleich) e, como visto na conclusão da $K p V$, de modo originário. Ao passo que, no $\S 23$ da $K U$, a efusão das forças vitais que o sentimento do sublime provoca só surge de modo indireto (indirecte) e é consecutiva (folgenden) à precedente inibição dessas mesmas forças vitais. Se, portanto, na teoria do sublime estético na $K U$ são distinguidos por Kant, de maneira evidente, um primeiro movimento (ainda que instantâneo [augenblicklich]) e um segundo a este sucessivo e contrário (ainda que subitamente [sogleich] consecutivo), de certo não contemporâneos entre eles;

11 Cf. BRANDT 2003, p. 85-104. 
diferentemente, na $K p V$, a ideia de personalidade, ao ocasionar o sentimento do respeito, nos mostra a sublimidade como um único momento em que elevação e rebaixamento ocorrem concomitantemente, ou seja, como um único momento em que o rebaixamento nada é senão outro modo de olharmos para a elevação, estando aquele a esta, digamos, como o negativo à fotografia. Aliás, não parece-nos ser escolhida casualmente por Kant a expressão: "vor Augen stellt", acreditamos, no intuito de ressaltar a unidade (visual) de como a sublimidade moral nos se apresenta.

Dando continuidade à passagem do $\$ 23$ da KU, Kant afirma que

também é incompatível com atrativos, e enquanto o ânimo não é simplesmente atraído pelo objeto, mas alternadamente também sempre de novo repelido por ele, a complacência do sublime contém não tanto prazer positivo, quanto muito mais admiração ou respeito, isto é, merece ser chamada de prazer negativo (KU, AA 05:245.0509).

É exatamente enquanto movimento de mão dupla, descendente e ascendente, de inibição e efusão das forças vitais, que o sentimento do sublime estético não pode ser considerado um sentimento positivo (ou afirmativo), ou, ao menos, não só positivo, mas sempre de novo (immer wieder) negativo, a saber, um sentimento que jamais deixa de, em certa medida, nos provocar dor ${ }^{12}$. Contudo, parece que a introdução no sublime estético da admiração e do respeito, conforme Kant propõe ao fim dessa passagem da KU, aproxime a teoria do sublime estético, de um lado, à conclusão

12 Sobre a negatividade do sublime estético cf. GRACYK 1986, p. 49-56; BERTINETTO 2006, p. 124-151; DELGIORGI 2014, p. 25-35. 
da $K p V$, devido ao resgate da dupla conceitual da admiração e do respeito, de outro lado, ao próprio terceiro capítulo da Analítica da razão pura prática, que examina em que sentido e medida ao sentimento do respeito deve ser conferido caráter negativo. Voltaremos à suposta aproximação à conclusão da $K p V$ em seguida, agora focando no sentimento do respeito conforme abordado no terceiro capítulo da $\mathrm{Kp}$.

Realmente, ao definir as premissas da questão também no terceiro capítulo da Analítica da razão pura prática, Kant parece ser peremptório, quando afirma que, por rejeitar todas as inclinações sensíveis, "o efeito da lei moral como móbil é, portanto, apenas negativo"; que "o efeito negativo no sentimento (pelo prejuízo que ocorre às inclinações) é ele próprio sentimento"; e que a lei moral "tem de provocar, ao prejudicar todas nossas inclinações, um sentimento que pode ser chamado de dor" (KpV, AA 05:72.28-73.05). Em outras palavras, a ação de inibição, pela lei moral, da sensibilidade reverbera nesta última provocando, em geral, um tipo de sentimento negativo e doloroso. Após pouquíssimas linhas, porém, Kant especifica como a negatividade desse efeito da lei moral na esfera sentimental deve ser compreendida em seus pormenores.

Mas, visto que essa lei é ainda algo em si mesmo positivo, a saber a forma de uma causalidade intelectual, isto é, da liberdade, ela é ao mesmo tempo um objeto de respeito, na medida em que, opondo-se àquilo que é subjetivamente contrário, a saber, às inclinações em nós, ela enfraquece a arrogância, e, na medida em que a abate, isto é, a humilha, ela é um objeto de maior respeito e, portanto, também é o fundamento de um sentimento positivo, que não é de origem empírica e é conhecido a priori ( $\mathrm{KpV}, \mathrm{AA}$ 05:73.24-30). 
Mais uma vez podemos notar a ênfase colocada na contemporaneidade com que a lei moral, ao mesmo tempo (zugleich), provoca seja humilhação como respeito, sendo aqui ulteriormente ressaltado que este se dá na medida em que (indem) se dá aquela, e que, com isso (mithin), a lei moral, que Kant descrevera inicialmente como causa de um sentimento negativo, é também (auch) causa de um sentimento positivo $^{13}$.

A teoria do sublime aqui exposta contrasta com toda evidência com a apresentada na $K U$, em que, conforme visto, Kant atribui ao sublime dois movimentos distintos. $\mathrm{Na}$ $K p V$ Kant reconhece um único momento, que poderíamos dizer une à nulificação da sensibilidade no homem sua imediata elevação de espírito graças à ao sentimento do respeito moral - e à ideia de personalidade - que abre à dimensão suprassensível, coexistente em nós à sensível. Mas como esse sentimento causado pela lei moral pode ser ao mesmo tempo negativo e positivo? Como, em outras palavras, pode ser explicada e deve ser lida essa dupla conotação? Nossa hipótese é que Kant esteja adotando um esquema análogo ao notório duplo ponto de vista aproveitado na terceira antinomia dialética da razão pura especulativa.

Embora fugazes, os acenos nesse sentido, no terceiro capítulo da Analítica da razão pura prática, mostram que

\footnotetext{
13 A mesma questão é rearticulada na página seguinte: "a lei moral humilha inevitavelmente todo homem, quando ele compara a propensão sensível de sua natureza com essa lei. Aquilo cuja representação, como fundamento de determinação de nossa vontade, nos humilha em nossa autoconsciência, na medida em que (indem) é positivo e que é um fundamento de determinação, desperta por si mesmo o respeito. A lei moral, portanto, é também (auch) subjetivamente fundamento do respeito" (KpV, AA 05:74.22-27).
} 
Kant está abordando o sentimento causado pela lei moral em um ser racional e finito, justamente como efeito cujas repercussões se manifestam tanto do ponto de vista da sensibilidade quanto do ponto de vista do suprassensível. Não parece casual Kant se referir a um único "efeito no sentimento (Wirkung aufs Gefühl)" definindo-o como "um efeito que, de um lado, é meramente negativo, mas, de outro lado, e certamente em vista do fundamento restritivo da razão prática pura, é positivo" (KpV, AA 05:74.34-75.02). Negatividade e positividade do sentimento originado pela lei moral no homem nada são senão duas perspectivas, dois modos (einerseits e andererseits) de olharmos para a relação que a própria lei moral instaura com nossa dimensão respectivamente sensível ou suprassensível, em vista (in Ansehung) da conexão mecânica e contingente de nossas inclinações, assim como da conexão universal e necessária com nossa pessoa, pela consciência de nossa liberdade.

O efeito negativo do sentimento (de desagrado) é patológico, assim como toda influência sobre ele e como todo o sentimento em geral. Contudo, enquanto efeito da consciência da lei moral, por conseguinte, em relação a uma causa inteligível, a saber, o sujeito da razão prática pura como legisladora suprema, esse sentimento de um sujeito racional afetado por inclinações chama-se certamente humilhação (desprezo intelectual), mas em relação ao seu fundamento positivo, a lei, chama-se ao mesmo tempo respeito por essa lei (KpV, AA 05:75.06-12).

Kant aqui explicita com tento a distinção subentendida nas passagens citadas logo anteriormente. Trata-se de demarcar, no interior de uma dinâmica geral - a que diz res- 
peito à habitual negatividade dolorosa que caracteriza todo sentimento de repressão da sensibilidade -, os traços específicos que tal dinâmica assume em um ser não apenas sensível, mas ao mesmo tempo dotado de consciência moral graças à sua racionalidade. Em tal ser, que é o ser humano, humilhação e respeito nada são senão dois modos dele chamar aquele sentimento que prova ao se deparar com a duplicidade de sua própria natureza, mais especificamente, os dois modos como reconhece operar sua apetitividade, a saber, sendo sua vontade passível de ser movida tanto pelas afecções sensíveis quanto por uma causa meramente inteligível, da qual de imediato o ser humano é de imediato consciente e que de imediato permite-lhe representar-se a si memso - sob uma lei - como ser sensível sempre ao mesmo tempo também livre. Aliás, acrescenta explicitamente Kant, "na medida em que ela [a lei moral] elimina a resistência, a remoção de um obstáculo é avaliada, no juízo da razão, como equivalente à promoção positiva da causalidade" (KpV, AA 05:75.13-15). Portanto, o respeito nos apresenta apenas o modo como a lei moral, que é causa determinante (Bestimmungsgrund) objetiva da vontade, é por nós compreensível e compreendida como móbil (Triebfeder) subjetivo na máxima de nossa ação, havendo 'equivalência' entre rebaixamento e elevação.

Assim é constituído o móbil genuíno da razão prática pura; ele não é nenhum outro senão a própria lei moral pura, na medida em que ela deixa seguir os vestígios da sublimidade de nossa própria existência suprassensível e em que provoca subjetivamente nos homens conscientes ao mesmo tempo de sua existência sensível e da dependência, ligada a esta, de sua natureza muito afetada patologicamente, o respeito por sua mais elevada destinação (KpV, AA 05: 88.19-24). 
Correspondentemente ao sentimento em nós da sublimidade de nossa existência suprassensível, a lei moral gera o sentimento de respeito por nossa mais alta destinação, sendo que é também nesse momento que, ao mesmo tempo, subjetivamente, somos conscientes de nossas limitações sensíveis. Não há simples inibição de nossas forças vitais, mas sim a constatação da dupla natureza que nos caracteriza, constatação esta que é inevitável à medida que o sensível é por nós reconhecido como negativo contudo também complementar ao suprassensível. Sob outra perspectiva, quando se tratar de relacionar suprassensível e sensível do ponto de vista subjetivo da sublimidade do sentimento de respeito pela lei moral, poderíamos dizer que rearticula-se aquela contraposição entre as duas dimensões constitutivas da natureza humana, frequentemente frisada com dureza por Kant quando examinada do ponto de vista objetivo da própria lei moral ${ }^{14}$. De certo modo, a teoria do sublime moral ser desdobrada no interior do capítulo da Analítica da $K p V$ dedicado ao Triebfeder, representa mais um indício de que o suprassensível, embora preservado quanto à sua primazia moral sobre o sensível, no entanto, por ser aqui experimentado por um viés - o sentimental e subjetivo costumeiro à experiência da dimensão sensível, encontra-se afinal em trégua com esta última, não obstante o cenário geral de luta.

Por outro lado, a partir desses pressupostos, Kant pode destacar ao sentimento do respeito peculiaridade máxima entre todos os sentimentos, ao ponto de conferir-lhe singu-

14 Sobre a questão cf., por exemplo, REATH 1989, p. 284-302; GOY 2007, p. 337-360. 
laridade entre eles: o respeito pela lei moral e a sublimidade que ele nos apresenta relativamente a nós mesmos como pessoas, como seres inteligentes capazes também de autodeterminação racional, é um sentimento único, que nada compartilha como os demais sentimentos empíricos, a não ser a forma subjetiva. Eis porque, afinal, "o respeito está tão longe de ser um sentimento de prazer" ao mesmo tempo em que também, "por sua vez, está todavia tão longe de ser um desprazer" (cf. KpV, AA 05:77.17-33). O cotejo textual entre $K p V$ e $K U$ não apenas mostra como a proximidade entre as duas obras não é tão acentuada quanto aparece à primeira vista, mas até permite, no fundo, defender uma consistente divergência teórica, à medida que, com todas as letras, o sublime estético teorizado em 1790, ao conter respeito, é chamado de prazer negativo, ao passo que, conforme acabamos de ver, o sublime moral teorizado em $1787 / 88$, pelo viés do sentimento do respeito, não refere-se nem ao prazer nem ao desprazer, ou seja, exclui justamente o caráter estético.

Se, por um lado, lermos retrospectivamente a teoria do sublime na $K p V$ pelo viés da teoria do sublime na $K U$ encontra sérias dificuldades, também parece problemático afirmar que na $K U$ Kant esteja resgatando o sentimento de admiração e respeito apresentado na $K p V^{15}$. São lícitas, por-

15 Melissa McBay Merritt abraça essa mesma linha interpretativa, ao defender que "para especificar adequadamente o sublime estado de espírito, precisamos apreciar a significância do sublime no escopo mais amplo do projeto crítico de Kant”. Ainda assim, o raciocínio da intérprete desconsidera as ressalvas por nós sugeridas no que tange certa distância teórica entre $K p V$ e $K U$, e, mesmo diferenciando respeito de admiração - "a admiração, então, é contemplativa, enquanto o respeito é exortativo" - acaba reaproveitando a teoria do sublime moral da $K p V$ para ler a do sublime estético da KU (cf. MERRITT 2012, p. 37-49). 
tanto, mais algumas observações, referentes ao âmbito da sublimidade na $K p V$. Seguindo a linha interpretativa esboçada, tentaremos novamente apontar que a distância teórica entre o sublime moral da $K p V$ e o sublime estético da KU realça-se pela discrepância argumentativa entre as duas obras.

Ao apresentar "a diferença interna mais importante entre o sublime e o belo" (KU, AA 05:245.10), Kant conclui que, contrariamente à beleza da natureza que "revela-nos uma técnica da natureza que a torna representável como um sistema segundo leis (System nach Gesetzen)" e, devido à tal conformidade a fins (Zweckmäßigkeit), como "autossubsistente" (KU, AA 05:246.05-06), o sublime estético, por sua vez, enquanto dolorosa negatividade sempre reiterada, em primeiro lugar, não deveria poder ser referido a objetos não naturais, "pois o sublime da arte é sempre limitado às condições da concordância (Übereinstimmung) com a natureza" (KU, AA 05:245.12-13). Ademais, mesmo quando ocorre atribuição de sublimidade ao objeto da natureza, o fazemos de forma imprópria, pois

aquilo que, sem raciocínio, produz em nós e simplesmente na apreensão o sentimento do sublime, na verdade pode, quanto à forma, aparecer como contrário a fins para nossa faculdade de juízo, inconveniente à nossa faculdade de apresentação e, por assim dizer, violento para a faculdade de imaginação, mas apesar disso e só por isso é julgado ser tanto mais sublime.

Disso, porém, se vê imediatamente que em geral nos expressamos incorretamente quando denominamos sublime qualquer objeto da natureza, embora na verdade pensamos de modo inteiramente correto denominarmos belos numerosos objetos da natureza; pois como pode ser caracterizado com uma expressão de aprovação o que em si é apreendido como contrário a fins? (KU, AA 05:245.16-25). 
A resposta kantiana a essa pergunta, como é notório, frisa que o objeto, inclusive o da natureza, "é apto à apresentação de uma sublimidade que pode ser encontrada no ânimo, pois o verdadeiro sublime não pode estar contido em nenhuma forma sensível" (KU, AA 05:245.26-27) ${ }^{16}$. Na $K p V$ Kant não distingue o sublime do belo, tampouco limita o sublime ao objeto da natureza, nem, quando refere o sublime à natureza, diferencia entre um verdadeiro sublime (eigentliches Erhaben) e um sublime dito apenas impropria e incorretamente. Pelo contrário, na $K p V$, como podemos observar na conclusão da obra, Kant propõe apenas um único gênero de sublimidade, não obstante sua diferenciação específica interna, sendo que, em todo caso, não apenas o sublime não é contraoposto à conformidade a fins (não é tratado como zweckwidrig), mas sobretudo é pensado em conformidade tanto às leis naturais, no caso do objeto de natureza (em especial, sendo nosso corpo destinado a desaparecer como agregado material determinado, conforme a causalidade mecânica que rege qualquer corpo), quanto ao fim último do ser humano, no caso da moralidade (notadamente a sublimidade moral coadunando com o sentimento de respeito - que a lei moral suscita em nós - pela destinação mais elevada do ser humano enquanto pessoa, ou seja, segundo a conexão necessária do fim em si).

Ainda no terceiro capítulo da Analítica da razão pura prática, antes de tratar da ideia de personalidade e visando introduzi-la, Kant não deixa de ser enfático ao reportar-se ao dever como sublime:

16 Para um exame da centralidade dos objetos e fenômenos naturais na teoria do sublime estético na KU, cf. BRADY 2013, p. 6 e 79-84. 
Dever! Ó nome grandioso e sublime ${ }^{17}$, que não abrange em si nada a bel prazer, nada que traga consigo a adulação, mas que requer a submissão, que non entanto, para mover a vontade, não ameaça com nada que aterrorize e suscite no ânimo repugnância natural, mas simplesmente põe uma lei que encontra por si mesma acesso ao ânimo (KpV, AA 05:86.20-24) $)^{18}$.

Sublime é o dever, que nos se impõe, objetivamente, como lei moral e, subjetivamente, como sentimento do respeito. $\mathrm{O}$ respeito, por sua vez, não refere-se aos objetos da natureza, tampouco aos que possam provocar medo ou repulsão, mas exclusivamente à lei moral e aos seres humanos, considerados não em sua animalidade ou como corpos materiais, mas como pessoas capazes de moralidade. Mesmo a lei moral originando o respeito como sentimento de submissão, este sempre se caracteriza por certa sua atratividade racional, longe de qualquer aleatoriedade ameaçadora que objetos da natureza podem suscitar, por sua incomensurabilidade e, portanto, incompreensibilidade ${ }^{19}$.

17 Cf. supra, final da nota 7.

18 Da seguinte maneira Kant encaminha a sublimidade do dever rumo à ideia de dignidade da personalidade: "qual origem lhe é digna [à lei] e onde se encontra a raiz de sua nobre linhagem [...], raiz cuja descendência é a condição inflexível daquele valor (Werths) que os homens unicamente podem dar a si mesmos? Não pode ser nada menos do que aquilo que eleva (erhebt) o homem acima de si mesmo (como uma parte do mundo sensível), que o conecta a uma ordem das coisas que apenas o entendimento pode pensar [...]. Não é nada senão a personalidade (Persönlichkeit), isto é, a liberdade e a independência do mecanismo da natureza" (KpV, AA 05:86.25-87.04). Ou, como Kant afirma pouco mais para frente, é unicamente pela personalidade que os seres humanos são fins em si mesmos (cf. KpV, AA 05:87.26-27). Para uma análise da dignidade como sublimidade (focada sobretudo na GMS), cf. SENSEN 2009, p. 309-331.

19 Para uma leitura que enfatiza o caráter tanto sublime quanto alegre da moralidade, cf. MERRITT 2017, p. 447-467. 
$\mathrm{O}$ respeito se dirige sempre às pessoas, nuncas às coisas. Estas podem despertar em nós inclinação e quando se trata de animais (por exemplo, cavalos, cachorros, etc.) até mesmo amor ou também medo, assim como o mar, um vulcão, um animal feroz, mas nunca respeito. Algo que se aproxima mais desse sentimento é a admiração e esta, enquanto afeto, o espanto, também pode se dirigir às coisas, por exemplo, às montanhas que se elevam até o céu, à grandeza, magnitude e amplitude dos corpos celestes, à força e velocidade de alguns animais, etc. Mas nada disso é respeito (KpV, AA 05:76.21-27).

Desses pressupostos segue uma dupla consequência. Conforme visto, na KU o sublime estético, que, ao contrário do belo, refere-se só ao objeto de natureza, pode ser chamado também de prazer negativo por conter indiferentemente "admiração ou respeito". Bastaria recordar à peculiaridade singular com que Kant caracteriza o sentimento do respeito na $K p V$, quanto à exclusão da esfera estética, para impedir que o uso indistinto entre admiração e respeito, na $K U$, remeta aos dois sentimentos conforme retratados na $K p V$. A isso acrescente-se que Kant faz questão de diferenciar explicitamente, na $K p V$, o sentimento do respeito do da admiração, talvez justamente por serem os dois comumente pensados como idênticos. A analogia que Kant reconhece haver entre os dois sentimentos, é balizada por um exame cuidadoso. Se na $K p V$ é aceito que admiração e respeito articulem o sublime - a sublimidade, todavia não referindo-se, na $K p V$, apenas ao objeto de natureza, como na $K U$-, por outro lado, e justamente no interior do sublime, admiração e respeito são relativos, ainda na $K_{p} V$, respectivamente ao objeto da natureza e às pessoas, enquanto habitadas pela lei moral. Nesse sentido é sintomática outra passagem, ainda no terceiro capítulo da Analítica da razão pura prática, em que Kant, debruçando-se sobre os ta- 
lentos humanos, após evidenciar admiração e respeito aparentarem analogia entre eles, esclarece em que sentido deve poder se pensar essa analogia.

Contudo, quando se olha mais de perto, nota-se que [...] esse respeito que nós demonstramos por uma tal pessoa (mais propriamente, pela lei que o exemplo dessa pessoa nos exibe) não é, portanto, mera admiração; o que se confirma também pelo seguinte: o séquito comum de admiradores perde todo o respeito por um homem (como Voltaire, por exemplo) quando acredita ter se informado de algum modo sobre a maldade em seu caráter, mas o verdadeiro erudito continua sempre sentindo esse respeito ao menos do ponto de vista de seus talentos (KpV, AA 05:78.03-15).

Kant parece brincar com a analogia entre admiração e respeito, quando, no fim da passagem recorre ao primeiro sentimento, esperando-se pelo segundo. $\mathrm{Na}$ verdade, a sugestão teórica de que respeito não deve ser igualado à mera admiração, é retomada também pela distinção entre o ponto de vista do seguidor comum e o especializado do erudito, pois este último, afinal, deixa de se referir ao caráter moral do outro, ou seja, não considera o outro enquanto pessoa, mas limita-se a considerar o profissional, o técnico habilidoso, o virtuosista; portanto, a rigor, inclusive o erudito respeita os talentos de outrem apenas no sentido próprio da admirá-los.

Kant oferece também - desdobrando-se assim a dupla consequência anunciada - a chave de leitura para compreendermos com maior exatidão a substituição do sentimento de reverência pelo sentimento de respeito na caracterização da sublimidade na conclusão da $K p V$. Como visto, o par conceitual mencionado no primeiro movimento do raciocínio (admiração e reverência) é substituído por outro par 
no segundo movimento (admiração e respeito), permanecendo naquela altura não resolvido se ambos estes últimos sentimentos, assim como os primeiros dois nomeados, referiam-se indistintamente tanto ao objeto da natureza quanto à moralidade; ou se a introdução do respeito visava enfatizar aquela diferença específica no interior da própria sublimidade, conforme abordado por Kant logo antes do início do segundo movimento argumentativo na conclusão, ao discriminar respectivamente o sublime como sentimento aniquilador quando relacionado ao objeto físico, material, corpóreo, e o sublime como sentimento de elevação quando relacionado à moralidade. $\mathrm{O}$ detalhamento apresentado na citação anterior sugere que esta última opção de leitura seja mais plausível, sendo que, na $K p V$, o sentimento de admiração especificaria mais estreitamente a sublimidade referente ao objeto de natureza, ao passo que o sentimento de respeito, ao substituir o de reverência, seria o mais adequado à sublimidade referente à lei moral.

Se assim for, mais uma vez, releva-se a distância teórica entre a teoria do sublime moral presente na $K p V$ e a do sublime estético presente na $K U$, desta vez a partir da conotação a priori da sublimidade que, na $K p V$, caracteriza só o sublime por respeito. Nem o amor, nem o medo, nem a admiração são equiparáveis ao sentimento do respeito. A altura das montanhas, a magnitude e amplitude dos corpos e espaços celestes, a extensão dos oceanos, a força dos vulcões, aos quais Kant apela também na KU para exemplificar os objetos da natureza que animam o sentimento a priori do sublime estético, na $K p V$ não originam sentimentos a priori, sendo apresentados como objetos de sentimentos 
empíricos, quais justamente a admiração, o amor, o medo, o espanto, etc., que Kant classifica como Affekte. Na KpV, os afetos dizem respeito ainda apenas à esfera patológica do prazer e desprazer que nada tem a ver com a determinação da vontade em sua dimensão pura prática à qual é reconduzível o sentimento do respeito, mesmo que apenas do ponto de vista subjetivo. $\mathrm{Na} K p V$, as grandiosidades da natureza em nenhum caso - tampouco quando consideradas por seu caráter violento - são reconhecidas como objeto de sublimidade pelo viés respeito, à medida que a origem deste último remonta à racionalidade da lei moral.

Esse sentimento (sob o nome de sentimento moral) é, portanto, provocado unicamente pela razão [...] serve apenas como móbil para adotar essa lei [a lei moral] em si mesma como máxima. Mas com qual nome poderíamos marcar de maneira mais conveniente esse sentimento peculiar, que não pode ser posto em comparação com nenhum sentimento patológico? Ele é de uma espécie tão singular que parece estar unicamente a comando da razão, e certamente da razão pura prática (KpV, AA 05:76.15-20).

Por outro lado, mesmo não cabendo reconstruir aqui a articulada e detalhada análise que Kant dedica os afetos como modificações dos sentimentos - na KU²0, baste lembrar a distinção entre afetos e paixões, a qual Kant retoma com ênfase em $1790^{21}$, inclusive para evidenciar a mudança

\footnotetext{
20 A teorização mais abrangente da relação dos afetos e com o juízo estético em geral, e o sublime em particular, é apresentada na Observação geral sobre a exposição dos juízos reflexivos estéticos, logo após o fim da Analítica do sublime (cf. KU, AA 05:240-244).

21 Silenciada na GMS assim como na KpV, cujo eixo teórico principal é a legitimação de uma única causa determinante pura a priori da vontade em face dos móbiles sensíveis, a distinção entre afetos e paixões é, contudo, estabelecida desde a década de 70, quando Kant, em suas Lições de antropologia, afasta-se da psicologia empírica de Baumgarten, que assimila as paixões aos afetos, e adere à proposta teórica de Hutcheson, que distingue entre os afetos como modificações do sentimento e as paixões como modificações do desejo (cf. FRIERSON 2014, p. 94-113 e WOOD 2014, p. 133-150).
} 
intercorrida depois de 1788 com relação à possibilidade de conferir, em certa medida, caráter a priori aos sentimentos também em âmbito estético. Em outras palavras, afetos e paixões deixam de ser examinados, na $K U$, apenas por sua natureza empírica, passando a ser avaliada por Kant a possibilidade de legitimá-los no interior da teoria do sublime estético. Como é notório, apenas a esfera sentimental mediante os afetos participa do sublime estético, pois, mesmo inibindo o princípio no qual se fundamenta o juízo sobre o sublime, a saber, a liberdade suprassensível, interagem com esta sem eliminá-la, como, ao contrário, fazem as paixões (cf. KU, AA 05:272.03 nota).

Aliás, ao resgatar o caráter impetuoso e impremeditado dos afetos de encontro ao duradouro e refletido das paixões (cf. idem), Kant acaba divaricando ainda mais as premissas da teoria da sublimidade entre $K U$ e $K p V$. Nesta última, os sentimentos empíricos e suas articulações afetivas, mesmo que diferenciados especificamente do sentimento de respeito pela lei moral, ainda parecem ganhar, por assim dizer, certa compreensibilidade à luz do ponto de vista moral. Exemplo disso é oferecido justamente pela admiração: por ser análoga ao respeito, ela é portadora de "uma perfeita similaridade de relações entre duas coisas muito dissemelhantes" (Prol., AA 04:357.28), ou seja, se manifesta de certo modo conforme ao objeto de natureza que a suscita, assim como o respeito o faz com relação à moralidade. Afinal, a admiração e até o espanto pelo céu estrelado sobre de nós expande ao infinito nossa conexão com o universo, anulando sim nossa própria individualidade, mas, em sentido análogo ao do respeito pela lei moral, sem ameaçar ou 
aterrorizar, isto é, nos conciliando com aquela infinitude que, à primeira vista, escapa à nossa compreensão. Afinal, é levando em conta a racionalidade pura prática que a sublimidade é teorizada na $K p V$. Ao passo que, na $K U$, como é notório, será a imaginação a decodificar a infinitude em termos para nós compreensíveis. Tratar-se-á de uma faculdade digamos mais inquieta que a razão pura prática, menos categórica, de certo, desprendida da necessidade de uma palavra final sobre o incomensurável. E, talvez, a centralidade da imaginação na $K U$ deva-se justamente a uma diferente concepção da sublimidade, atrelada a um senso de ameaça e terror constantemente à nossa espreita toda vez que contemplarmos o infinito. Os afetos que então surgem, violentos e inesperados, não deixam margem a uma conciliação definitiva, apenas permitindo ao nosso ânimo uma pausa temporária. A compreensão estética do sublime, diferentemente de sua compreensão moral, quase escorrega de nós, sempre, de novo, em um vaivém alimentado por uma repulsão visceral que intensifica uma atração - inexplicável do ponto de vista moral e ainda menos lógico - por algo, agora sim, pensado como verdadeiramente outro com relação a nós. Daí a necessidade de busca por um terceiro caminho, o da sublimidade estética, apto à significação de uma natureza reconhecida não só como não irênica, mas essencialmente voltada à aniquilação do ser humano.

Resumindo de maneira esquemática, na $K p V$ e diferentemente da $K U$, para Kant o sublime refere-se tanto ao objeto de natureza, quanto à moralidade, manifestando-se sob forma de sentimento respectivamente de admiração e de respeito; em ambos os casos o sentimento de humilhação 
da sensibilidade não nos aterroriza, antes, nos lembra olharmos para nosso duplo destino como adequado e conforme à nossa dupla natureza de seres quer materiais quer morais; notadamente o sentimento do respeito, graças à hibridez sui generis que o caracteriza, mostra eminenter a aparentemente paradoxal ambivalência sentimental própria do sublime, de abate que ao mesmo tempo eleva. Kant ultrapassará rapidamente a concepção da sublimidade exposta na $K p V$, encaminhando-se rumo a uma diferente teoria do sublime em chave propriamente estética pelo viés da imaginação, já em 1789, conforme testemunhado por uma anotação cuja datação remonta àquele ano.

A cultura do gosto é exercício anterior à moral.

Do sublime. É aquilo em cuja representação (da imaginação) o ânimo sente sua própria destinação ou disposição a expandir-se até o que excede todos os padrões dos sentidos.

É como a descoberta de um abismo na nossa própria natureza, que se estende além dos limites dos sentidos. - Daí o temor que nos prende. - Um medo sempre dissipado pela consideração da nossa própria segurança e de uma curiosidade grande demais para nossa faculdade de compreensão.

Montanhas e planícies. Como se fosse a natureza em sua violenta destruição, daí a fábula dos gigantes. - Conduz à exaltação da imaginação, e lá o ânimo cai no medo da tensão excessiva e da loucura. Burke - Milton - Klopstock. A decida de Eneias aos ínferos. - A noite é sublime o dia belo. Desertos habitados por espíritos. - Antigos castelos abandonados.

- A profundeza do ânimo na moralidade é sublime (R. 993, AA 15:438-439).

Quando o incomensurável for reconhecido em toda sua estraneidade, uma curiosidade, insana para a sã razão, impele a imaginação (Einbildungskraft) além da compreensão (Fassungskraft) pelos limites dos próprios sentidos. À moral 
precede a vivência do gosto por uma natureza titânica que só é dita adequadamente pela arte da fábula mítica. Já a noite não mostra mais, soturna, o céu estrelado, nem a lei moral eleva, mas abre às profundezas do abismo que é em nós.

Abstract: The paper aims to propose a reading of the theory of sublimity in the Critique of practical reason, based on the analysis of passages in which, in particular at the conclusion of the work and in the third chapter of the Analytic of pure practical reason, Kant offers textual support to highlight a certain theoretical distance from the aesthetical conception of the sublime, later presented in the Critique of judgment, notably in the general formulation of \$23. So, with a background perspective contrasting with interpretations that bring the second and third Critiques closer, with regard to the sublime, we suggest that in these two works there are variations about both the dynamics involved in the sublime and its object of reference, as well as about the characterization of the feelings of admiration and respect through which, according to Kant, the sublime expresses itself.

Keywords: Kant; sublime; respect; admiration.

\section{REFERÊNCIAS}

\section{OBRAS DE KANT}

KANT, I. Kants Gesammelte Schriften (AA). Preußische Akademie der Wissenschaften (Vol. 01-22); Deutsche Akademie der Wissenschaften (Vol. 23); Akademie der Wissenschaften zu Göttingen (Vol. 24-29), 1900-1997:

Prolegomena zu einer jeden künftigen Metaphysik, die als Wissenschaft wird auftreten können (Prol, AA 04:255383); MORÃO, Artur (trad.). Prolegômenos a toda a metafísica futura que queira apresentar-se como ciência. Lisboa: Edições 70, 1988.

\section{Grundlegung der Metaphysik der Sitten (GMS, AA}


04:387-463); ALMEIDA, Guido A. de (trad.). Fundamentação da metafísica dos costumes. São Paulo: Discurso Editorial/Barcarolla, 2009.

Kritik der praktischen Vernunft (KpV, AA 05:03-163); de HULSHOF, Monique (trad.). Crítica da razão prática. Petrópolis: Vozes, 2012.

Kritik der Urteilskraft (KU, AA 05:171-485); ROHDEN, Valério; MARQUES, António (trad.). Crítica da faculdade do juízo. Rio de Janeiro: Forense Universitária, 2012 (1993).

\section{Demais TEXTOS UTILIZADOS}

BECK, L. W. A Commentary on Kant's Critique of Practical Reason. Chicago: University of Chicago Press, 1984 (1960).

BERTINETTO, A. Negative Darstellung. Das Erhabene Bei Kant Und Hegel. Internationales Jahrbuch des Deutschen Idealismus / International Yearbook of German Idealism, v. 4, 2006, p. 124-151.

BRADY, E. The Sublime in Modern Philosophy. Cambridge: Cambridge University Press, 2013.

BRANDT, R. (2003). The Vocation of the Human Being. In: JACOBS, Brian; KAIN, Patrick (eds.). Essays on Kant's Anthropology. Cambridge: Cambridge University Press, 2003, p. 85-104.

CLEWIS, R. R. The Place of the Sublime in Kant's Project. Studi Kantiani, v. 28, 2015, p. 149-68.

COHEN, A. Kant's Answer to the Question 'What is 
Man?' and its Implications for Anthropology. Studies in History and Philosophy of Science, v. 39, n. 4, 2008, p. 506-514.

DELGIORGI, K. The Pleasures of Contra-Purposiveness: Kant, the Sublime, and Being Human. Journal of Aesthetics and Art Criticism, v. 72, n. 1, 2014, p. 25-35.

ERTL, W. Persons as Causes in Kant. In: PALMQUIST, Stephen R. (ed.). Cultivating Personhood: Kant and Asian Philosophy. Berlin/New York: de Gruyter, 2010, p. 217230.

FRIERSON, P. R. What is the Human Being? New York: Routledge, 2013.

. Passions and affects. In: COHEN, Alix (ed.). Kant's lectures on anthropology: A critical guide. Cambridge: Cambridge University Press, 2014, p. 94-113.

GERHARDT, V. Die Menschheit in der Person des Menschen. In: KLEMME, Heiner F. (ed..). Kant Und Die Zukunft der Europäischen Aufklärungkant/Kant and the Future of the European Enlightenment. Berlin/New York: de Gruyter, 2009, p. 269-291.

GOY, I. Immanuel Kant über das moralische Gefühl der Achtung. Zeitschrift für Philosophische Forschung, v. 61, n.3, 2007, p. 337-360.

GRACYK, T. A. Sublimity, Ugliness, and Formlessness in Kant's Aesthetic Theory. Journal of Aesthetics and Art Criticism, v. 45, n 1, 1986, p. 49-56. 
GUYER, P. Symbols of Freedom in Kant's Aesthetics. In: - Values of Beauty: Historical Essays in Aesthetics. Cambridge: Cambridge University Press, 2005, pp. 222241.

LOUDEN, R. B. Kant's Human Being: Essays on His Theory of Human Nature. Oxford: Oxford University Press, 2011.

MERRITT, M. McBAY. The Moral Source of the Kantian Sublime. In: COSTELLOE, Timothy M. (ed.). The Sublime: from Antiquity to the Present. Cambridge: Cambridge University Press, 2012, p. 37-49.

. Sublimity and Joy: Kant on the Aesthetic Constitution of Virtue. In: ALTMAN, Matthew (ed.). The Palgrave Kant Handbook. London: Palgrave Macmillan, 2017, p. 447-467.

MOHR, G. Personne, personnalité et liberté dans la Critique de la Raison pratique. Revue Internationale de Philosophie, v. 42, n. 166, 1988, p. 289-319.

NOLLER, J. Reason's Feeling: A Systematic Reconstruction of Kant's Theory of Moral Respect. SATS. Northern European Journal of Philosophy, v. 20, n. 1, 2019, p. 118.

REATH, A. Kant's Theory of Moral Sensibility. KantStudien, v. 80, n. 3, 1989, p. 284-302.

SENSEN, O. Kant's Conception of Human Dignity. KantStudien, v. 100, n. 3, 2009, p. 309-331.

WOOD, A. Empirical Desire. In: COHEN, Alix (ed.). 
Kant's lectures on anthropology: A critical guide. Cambridge: Cambridge University Press, 2014, p. 133-150. 
